\title{
Encouraging healthier choices in supermarkets: a co-design approach
}

\author{
Bogomolova, S., Carins, J., Dietrich, T., Bogomolov, T. and Dollman, J. 2021, \\ "Encouraging healthier choices in supermarkets: a co-design approach", European \\ Journal of Marketing, Vol. ahead-of-print No. ahead-of-print. \\ https://doi.org/10.1108/EJM-02-2020-0143.
}

Acknowledgements: The authors are grateful to SA Health Healthy Towns Challenge for financial support of this work, and to The Barossa Co-op for their invaluable partnership and in-kind contribution which made this project possible.

\begin{abstract}
Purpose - This research describes and evaluates the co-creation of a programme called "A Healthy Choice". Underpinned by design thinking (DT), this study aims to improve the healthfulness of food choices in supermarkets among consumers to promote their well-being. Design/methodology/approach - The research features two studies. Study 1 included five co-design workshops with consumers and staff $(n=32)$ to develop a consumer-centred programme. The findings supported the design and implementation of a programme evaluated in Study 2 (an ecological trial). The programme modified a supermarket environment to increase the prominence of healthier products (shelftalkers and no discount), ran positive food experiences (cooking and label reading workshops) and was supported by a community-wide information campaign in social and local print media.

Findings - A total of 15 new strategies were developed by consumers and staff to support health and wellbeing in supermarkets. Feasibility discussions and staff voting contributed to the development and storewide implementation of the programme. Evaluation showed that the programme was effective in increasing consumer knowledge of healthier food choices (measured via public survey). Sales analysis showed mixed results; sales increased for promoted products in some categories, but there was no effect in others.
\end{abstract}

Research limitations/implications - Given the real-world setting in which this programme and its evaluation were conducted, there were several innate limitations. The co-design process generated many more ideas than could be implemented, thus creating a healthy "pipe line" for the next iterations of the programme.

Practical implications - The key contribution of this work to supermarket intervention literature is the recommendation to change the paradigm of engagement between the key stakeholders who are typically involved in supermarket programs. Using the co-design and DT frameworks, the authors offer an example of stakeholders working together in close partnership to co-design and collaboratively implement a programme that promotes healthier choices.

Originality/value - This project contributes to the emerging body of empirical work using DT principles in the area of healthy food choices in supermarkets. A rigorously designed evaluation of a co-designed supermarket programme contributes to scholarly evidence on food well-being programs in supermarkets.

Keywords: Design thinking, Co-design, Healthy choices, Supermarket

Paper type: Research paper 


\section{Introduction}

Food consumption is an integral part of daily life that provides sustenance to support the body but also fulfils many other human needs, including pleasure and social connection (Bublitz et al., 2013). For some time, ecological models (Bronfenbrenner, 2005) have conceptualised health as being determined by both individual factors and surrounding influences. However, more recent thinking has conceptualised the need for food well-being as 'a positive psychological, physical, emotional, and social relationship with food at both the individual and societal levels' (Block et al., 2011) which, by definition, necessitates the recognition of influences broader than any individual. This thinking can be extended to include retail settings which have been shown to influence (mostly negatively) the healthfulness of food choices, thereby affecting dietary behaviours (Sonntag et al., 2015). These choices in turn contribute to health challenges for society, such as the obesity pandemic (Swinburn et al., 2011), and reduce the ability of individuals, families, and society to achieve well-being. In developed countries, over $70 \%$ of food comes from supermarkets (Cohen and Babey, 2012). Therefore, supermarkets represent a major opportunity to improve healthfulness in choices (Houghtaling et al., 2019).

To design an effective programme, it is important to involve key stakeholders during its ideation, design, and implementation phases. Design thinking can guide consumer research during the development of innovative service environments, including supermarkets (Brown, 2008). Design thinking achieves this by being consumer-centric, while taking into consideration the perspectives of all relevant stakeholders (i.e., industry, policy; Lockwood, 2010). The present research argues that co-design can serve as a specific instance of Design Thinking (Trischler et al., In press) by empowering customers and other stakeholders to contribute as experts of their unique experiences. Co-design is a qualitative data collection method that is superior to traditional qualitative methods, such as focus groups and interviews, because it allows consumers to contribute to the ideation process in a more equitable and efficient way (Sanders and Stappers, 2008).

This study aimed to develop and evaluate a consumer-focused programme to encourage healthier food purchases in a supermarket, thus contributing to the food well-being of a community. The specific research objectives were:

- Research Objective 1 (Study 1): 'map out' and examine the process of co-designing and implementing a programme that encourages healthier choices in a real supermarket.

- Research Objective 2 (Study 2): evaluate the effectiveness of a co-designed programme for improving the healthfulness of food choices in a real supermarket.

Study 1 involved co-design sessions with consumers and staff; tasks included feedback on previous programmes and creation of new programme ideas. Study 2 developed a food wellbeing programme called 'A Healthy Choice' based on the co-design findings. The 13-week programme consisted of shelf-talkers, cooking demonstrations, label-reading supermarket tours, and a community-wide information programme. A rigorous sales analysis (based on SKU, category, and weekly data) evaluated the effectiveness of the programme.

The particular novelty and contributions of this research are:

- Integrating a co-design framework into the design thinking approach to ensure that consumer and staff views were directly incorporated into the development of this largescale programme. Both groups developed distinctly new ideas and enriched existing 
ones, thus demonstrating the value of co-design. This is a crucially important contribution, given the relative novelty of co-design methods.

- Designing and evaluating a programme for a retail environment that promotes healthier choices, while creating pleasurable experiences for consumers to enjoy when spending time, socialising, and satisfying their food needs in an ethos of food well-being.

- Providing a detailed 'road map' for researchers and industry practitioners for co-design workshops, idea generation, and rigorous evaluation. Due to the very complex nature of ecological trials in retail settings, further evidence of a programme with a detailed analysis of what worked and did not is a valuable contribution.

\section{Background and theoretical framework}

\section{Food well-being}

Today's society is challenged by an increasing prevalence of health issues, with many linked to food consumption. Traditionally, health has been conceptualised as involving within and beyond individual factors (Bronfenbrenner, 2005). When it comes to food, individuals are seen as interacting with the surrounding food environment in reciprocal ways (Roberto et al., 2015). Proposed solutions have emphasised personal responsibility and development of self-efficacy to overcome external influences or exercise restraint in environments favouring behaviours that increase health risks (Hoek and Jones, 2011). Recently, these perspectives have been judged as functional and paternalistic notions of food choice, resulting in a shift towards a more positive integrative approach to food consumption called 'food well-being' (Scott and Vallen, 2019, Block et al., 2011). This holistic view recognises that food is consumed to provide sustenance but also opportunities for sharing and social connection, pleasure, and comfort (Bublitz et al., 2013). Furthermore, food consumption contributes to well-being not only by enabling health, but also by providing satisfaction, enjoyment, and interesting and shared experiences, often intertwined with familiar or enticing rituals, practices, and locations (Addis and Holbrook, 2019). Critically for this research, the conceptualisation of food well-being shifts the focus from food, as functional assemblies of nutrients needed by individuals to regulate and achieve health, to people, who require food and food practices to provide positive experiences that contribute to their own well-being, as well as that of their communities and society.

The food well-being framework has been used to analyse contexts and understand leverage points, but less so to intervene. For example, Bublitz et al. (2019) implemented the food wellbeing framework to analyse the programmes and advocacy efforts of the Hunger Task Force to identify future pathways to understand and address hunger, as part of advancing food wellbeing. To the authors' knowledge, our research is the first study that has adopted the food wellbeing framework to develop an intervention programme.

\section{Supermarkets as food well-being contexts}

Food retail settings, particularly supermarkets, contribute to food well-being through five primary domains: food availability, food literacy, food socialisation, food marketing, and food policy (Block et al., 2011). Food retailers can 1) increase food availability and accessibility, 2) improve literacy by the provision of information and procedural knowledge, 3 ) introduce and normalise consumption of foods and socialise food rituals and practices, and 4) conduct food marketing through efforts to influence consumers' attitudes and behaviours, and 5) create organisation-wide food policy (Block et al., 2011, Parkinson et al., 2017). 
Therefore, retail settings provide a location for integrated and multifaceted strategies for food experiences that may contribute to food well-being. To the best of our knowledge, no studies have yet adapted the food-wellbeing framework to the context of supermarket intervention.

Supermarkets in developed countries supply over $70 \%$ of food eaten by consumers (Cohen and Babey, 2012). This makes the supermarket environment a particularly attractive location for food well-being programmes, due to the high number frequent shoppers and the potential to influence the critical moment when a consumer makes food purchase decisions. This 'moment of truth' is when consumer choices could be swayed towards healthier choices or not. Table 1 presents our proposed operational definitions of each food well-being dimension in the context of supermarkets.

Table 1: Conceptual definition of food well-being (Block et al., 2011)

\begin{tabular}{|c|c|c|}
\hline Food well-being & Domain & Operational definition \\
\hline \multirow{5}{*}{$\begin{array}{l}\text { A positive psychological, } \\
\text { physical, emotional, and } \\
\text { social relationship with } \\
\text { food at both individual } \\
\text { and societal levels. } \\
\text { - Holistic and }\end{array}$} & Food availability & $\begin{array}{l}\text { The distribution and availability of } \\
\text { food at home, at work, in restaurants, } \\
\text { in grocery stores, and in the wider } \\
\text { community }\end{array}$ \\
\hline & Food literacy & $\begin{array}{l}\text { The ability, opportunity, and } \\
\text { motivation to identify, understand, } \\
\text { interpret, communicate, and use } \\
\text { information about food in various } \\
\text { contexts }\end{array}$ \\
\hline & Food socialisation & $\begin{array}{l}\text { The processes that consumers use to } \\
\text { learn about food, its role, and food } \\
\text { well-being within a person's cultural } \\
\text { realm }\end{array}$ \\
\hline & Food marketing & $\begin{array}{l}\text { The use of the seven Ps of marketing } \\
\text { to influence consumers' attitudes and } \\
\text { behaviours toward foods }\end{array}$ \\
\hline & Food policy & $\begin{array}{l}\text { Several types of policies related to } \\
\text { food systems at international, national, } \\
\text { state, and local levels to more } \\
\text { effectively align food production and } \\
\text { distribution with dietary } \\
\text { recommendations and principles of } \\
\text { sound environmental stewardship }\end{array}$ \\
\hline
\end{tabular}

A substantial body of work has been conducted in supermarkets to improve the healthfulness of consumer food choices (for systematic reviews see e.g., van't Riet, 2013, Escaron et al., 2013, Liberato et al., 2014). Reviews show that past programmes have generally had a positive effect (in terms of sales increases in promoted healthy products), with some mixed results across different product categories. One review of 17 studies found that five had positive effects, eight mixed results (with varied results for different product categories), and four had no effect (see Tables 1 and 4 in van't Riet, 2013). Similarly, another review of 13 interventions found that eight resulted in increased purchases of the targeted products (Escaron et al., 2013). The vast majority of successful programmes included some form of point-of-sale signage as an essential element. Programmes that combined point-of-sale signage with other elements, such as community-wide information campaigns, were more effective than those with point-of-sale 
signage alone (Escaron et al., 2013). Financial incentives, such as discounts, have also effectively increased sales of healthful foods in supermarket programmes (Liberato et al., 2014). Commercial marketing has also shown significant sales increases using price promotions (Neslin, 2002, Bijmolt et al., 2005). In summary, previous evaluations of supermarket programmes (e.g., van't Riet, 2013, Escaron et al., 2013, Liberato et al., 2014) suggest that point-of-sale signage (i.e., shelf-talkers), community-wide information or education campaigns, and financial incentives (discounts) may be effective strategies to improve healthful choices and in turn food well-being.

A marketing programme in a retail setting usually considers seven elements, which could be traced back to the original 'seven Ps' framework (Rafiq and Ahmed, 1995). In a supermarket context, they are: 1) product-foods and other physical products along with peripheral items that assist in making them available; 2) price - the physical and intangible costs of obtaining products or engaging in the provision of services such as food equipment; 3) place-the location where the service/provision takes place; 4) promotion-communication about the service/provision through media or service people; 5) people - service providers and customers who interact during the service/provision; 6) physical evidence-tangible elements of the service including equipment, design, and atmospherics, and 7) process - the flow of activities involved in food service/provision. These elements support the development of a holistic intervention.

\section{Co-design as a specific design thinking tool}

Addressing the need for collaborative involvement in design requires a process that can actively involve various stakeholders (Domegan et al., 2013), such as design thinking (DT). DT is an approach to solve complex problems and foster innovation by employing a diverse range of design tools (Elsbach and Stigliani, 2018). DT has been employed to improve a variety of service settings, ranging from health care to retail and information technology solutions (Brown, 2009). DT is characterised by a strong consumer-centric perspective that observes and engages with diverse views of relevant stakeholders such as experts, designers, customers, as well as industry and policy representatives (Lockwood, 2010).

One method of DT is co-design which empowers everyday customers and other stakeholders to contribute as experts of their unique experiences (Dietrich et al., 2017a). Co-design is a scientific method of qualitative data collection that aims to include consumers affected by a service mix (Trischler et al., In press). Co-design workshops are viewed as an improvement on more traditional qualitative methods (e.g., focus groups) because they allow consumers to contribute to strategy design as experts of their own experiences (Sanders and Stappers, 2008). Service design solutions informed through co-design have been shown to be more effective (David et al., 2019). Co-design may enhance existing DT frameworks given its end-user focus which often gets less attention in conventional design thinking processes. Therefore, co-design has the potential to improve the DT process by achieving greater consumer involvement throughout the various stages. 


\section{Study 1: Co-design workshops}

The research objective for Study 1 was to 'map out' and examine the process of co-designing and implementing a programme that encourages healthier choices in a real supermarket.

\section{Method}

This research was conducted in an Australian independent medium-sized supermarket. Local residents were invited through social and print media to attend co-design workshops conducted by the researchers. Five 90-minute co-design sessions were conducted in March 2019: four involving consumers and one comprised of retail staff. In addition to providing 'within group' feedback on ideas, staff provided 'across group' feedback on ideas generated by consumers, voting for the best programmes based on their understanding of feasibility and potential impact. All workshops were audio recorded with photographs taken of the ideas (captured as 'mud maps'). Participants were reimbursed for their time with $\$ 20$ vouchers and staff attended during paid work hours (no additional incentive was offered). Ethical clearance from the [name withheld during peer review] was obtained for the project [Protocol 200833].

The participant sample comprised 24 consumers and eight staff. The consumer group was broadly representative of the adult shopping population for the region, ranging in age, gender, family status, household size (Statistics, 2019, see Table 2). The staff from mid and senior management roles represented key retail and marketing departments.

Table 2: Demographics of co-design workshop participants (consumers $n=24$; staff $n=8$ )

\begin{tabular}{|l|r|c|c|}
\hline Characteristic & & Total $(\mathbf{\%})$ & Average (range) \\
\hline \multirow{2}{*}{ Gender } & Males & $7(22 \%)$ & - \\
\cline { 2 - 4 } & Females & $25(78 \%)$ & - \\
\hline \multirow{4}{*}{ Age } & $<25$ years & $3(9 \%)$ & - \\
& $26-35$ years & $2(6 \%)$ & - \\
& $36-45$ years & $8(25 \%)$ & - \\
& $46-55$ years & $7(22 \%)$ & - \\
\hline \multirow{3}{*}{ Co-op member } & $56-65$ years & $7(22 \%)$ & - \\
& $65+$ years & $5(16 \%)$ & - \\
\cline { 2 - 4 } & Member & $30(94 \%)$ & 17 years $(0-45)$ \\
\cline { 2 - 4 } & Non-member & $2(6 \%)$ & 3 persons $(0-8)$ \\
\hline \multirow{2}{*}{ Household } & Membership length & - & 1 child $(0-6)$ \\
\hline
\end{tabular}

Following the seven-step co-design process (Trischler et al., In press), the workshops included activities to sensitise participants by explaining the requirements of the workshop and familiarising them with the types of programme components intended for design, followed by facilitation of creativity and ideation to generate new programme concepts. Specifically, participants were first asked to complete a word association task individually to sensitise them to the topic of health and well-being, with a contextual focus on retail settings. This required participants to respond to each prompter word by writing an associated word. Prompter words were region, food, well-being, local, healthy choices, supermarket, being active, healthy habits, exercise, convenient, and fresh. Next, participants performed a written sentence completion 
task to activate experiences and aspirations related to their health and well-being. Sentence starters were: "For me, a good day is when I..."; "I am happiest when ..."; "Healthy living for me is..." To eat healthily I..."; "What stops me from being healthy is...". A short group discussion followed where participants shared key responses to develop rapport ahead of the creative tasks. The third task provided participants with visual stimuli and short descriptive sentences, describing strategies sourced from previous programmes. Participants were asked to review each strategy (28 in total covering seven broad themes) and record in their workbook which strategies they liked, felt neutral about, or disliked. A second group discussion followed inviting participants to share opinions on previous strategies. This third task served as a platform for participants to think about possible programme strategies in preparation for creatively designing their own programmes. Figure 1 shows examples of previous strategies presented to participants for feedback.

Figure 1. Examples of stimuli showing previous program strategies

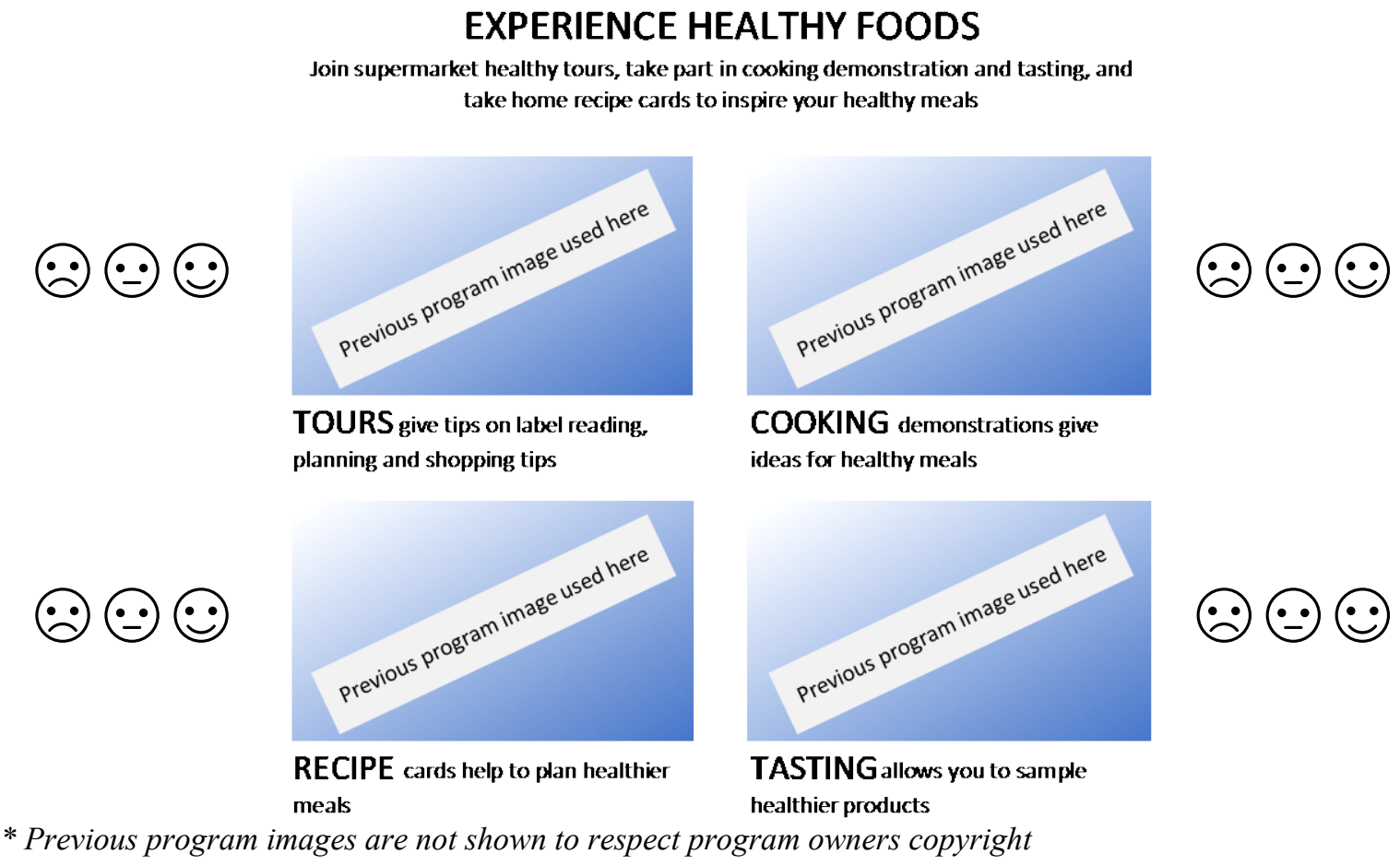

The final and main task in the co-design workshop was the creation of new programme ideas in the form of colourful 'mud maps'. Participants were separated into pairs or groups of three and provided with large sheets of paper, coloured pens, 'Blu Tack', scissors, and magazines (e.g., food, cooking, lifestyle, fashion, nature, and sporting magazines for as wide a range of images as possible). Participants were encouraged to create a visual concept for their programme, including a name, logo, retail store involved, and the main ideas for the programme in as much detail as possible. Each small group gave a 2-5 minute 'pitch' of their programme to the rest of the groups and researchers, after which questions or feedback from all in the room were welcomed. This final evaluative step provided an opportunity for researchers to ensure that participants had adequately captured their ideas. Indeed, the process of talking through the ideas and indicating them on the mud map dispelled ambiguity and prompted any last-minute additions (e.g., the title needed to be written on the map). 


\section{Analysis approach}

The co-design workshops generated textual responses and visual representations of ideas ('mud maps' on poster size paper). The analysis of these data focussed on synthesising the features of the programmes created by consumers and presented in the mud maps. The findings were used to produce insights for future programme design and testing.

The mud maps were examined and synthesised by two independent researchers based on the approach described by Braun and Clark (2006) as a theoretically flexible research method suited to a range of epistemologies. For this research, inductive and deductive approaches were blended by inductively generating themes to capture the 'ideas' of the participants and deductively exploring the data within the framework of the seven Ps service mix (Rafiq and Ahmed, 1995). This systematic analysis of the data against each theme and across the entire data set generated a thematic representation of the analysis and enabled the collation of participants' ideas towards developing comprehensive service offerings.

In general, participants viewed past strategies positively. Strategies they particularly liked were product-based strategies (local foods, fresh foods, and healthy foods for children), informative or promotional strategies (labels, displays, and signs), price-based strategies (discounts on healthy foods), as well as process-based strategies (sponsorship of local groups, recipe cards, tastings, market days, and advice from professionals).

\section{Results: generation of new programme ideas}

A total of 15 programme ideas were generated (11 by consumers and four by staff). Figure 2 shows two 'mud maps', one by consumers and one by staff.

Researchers placed no bounds on creativity; however, analysis found that the supermarket still dominated the place category. Of the other seven $\mathrm{P}$ categories, product, price, and process were the most frequently mentioned by consumers and staff. Providing a wide range of healthier products at competitive prices was particularly important. For example, Asian Food Experience, suggested the installation of a mini pop-up store within the supermarket with a rolling Asian theme. Participants explained that many Asian cuisines are rich in vegetables (i.e., Thai, Vietnamese), so cooking these meals will increase vegetable intake, thus making meals healthier. Participants suggested that local chefs could conduct food demonstrations instore and displays presenting all the ingredients for that dish together would ensure convenience for shoppers. Table 4 presents supermarket ideas coded across the seven Ps framework. 
Figure 2. Illustrations of the 'mud maps'

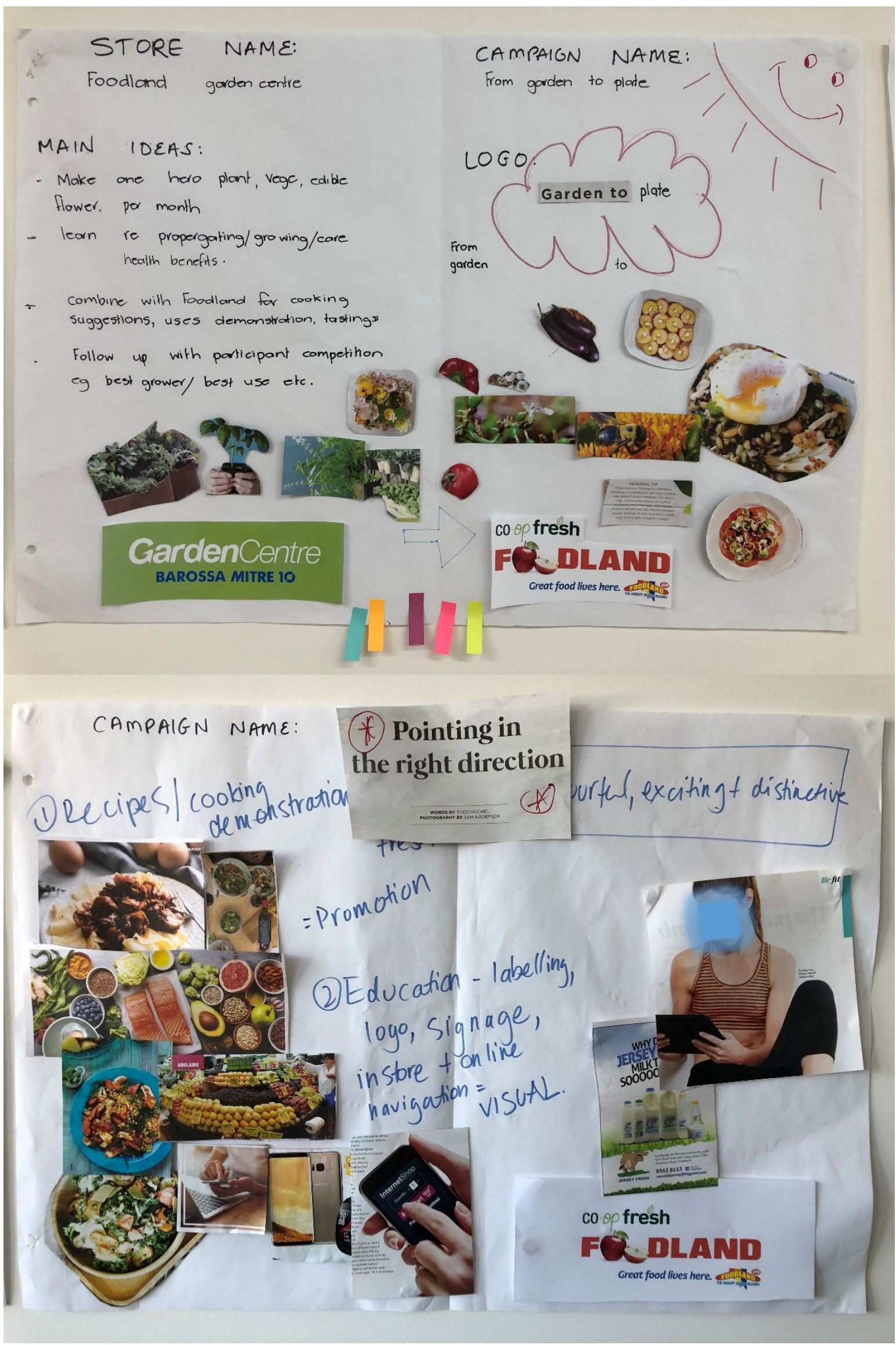


Table 3. Participants' program ideas coded across the seven Ps and compared to 'A Healthy Choice' program

\begin{tabular}{|c|c|c|c|c|c|c|c|}
\hline Seven Ps & Products / Services & Price & Place & Promotion & People & Physical evidence & Process delivery \\
\hline $\begin{array}{l}\text { Pointing in the } \\
\text { Right } \\
\text { Direction } \\
\text { (Group 5.1) }\end{array}$ & $\begin{array}{l}\text { Fresh produce } \\
\text { Signage (in-store, online) }\end{array}$ & $\begin{array}{l}\text { Healthy food purchases (cost) create } \\
\text { healthier eating (benefit). Time finding } \\
\text { healthy food (cost) is reduced (benefit). }\end{array}$ & Supermarket & Cooking demonstrations & Local dieticians & $\begin{array}{l}\text { Displays } \\
\text { Recipe cards } \\
\text { Labelling/Signage }\end{array}$ & $\begin{array}{l}\text { Labelling and signposting to make it } \\
\text { for consumers to find healthy foods a } \\
\text { fresh produce in store. }\end{array}$ \\
\hline $\begin{array}{l}\text { Market Day } \\
\text { (Group 1.3) }\end{array}$ & $\begin{array}{l}\text { Fruits and vegetables } \\
\text { Meal packs } \\
\text { Discount scheme }\end{array}$ & $\begin{array}{l}\text { Spending on healthy foods (cost) is } \\
\text { reduced (benefit). Time spent on food } \\
\text { preparation (cost) is reduced (benefit). }\end{array}$ & Supermarket & $\begin{array}{l}\text { Event (Market Day) } \\
\text { Cooking demonstrations }\end{array}$ & Whole community & $\begin{array}{l}\text { Meal packs } \\
\text { Displays } \\
\text { Demonstrations } \\
\text { Recipe cards } \\
\end{array}$ & $\begin{array}{l}\text { Periodic Market Day with cooking } \\
\text { demonstrations each day. Fresh produ } \\
\text { used, cost/serve provided. Ingredient } \\
\text { bundles (packs) for home preparation }\end{array}$ \\
\hline $\begin{array}{l}\text { From Garden } \\
\text { to Plate } \\
\text { (Group 2.1) }\end{array}$ & $\begin{array}{l}\text { Food plants } \\
\text { Healthy foods } \\
\text { Gardening information } \\
\text { Cooking demonstrations }\end{array}$ & $\begin{array}{l}\text { Time spent learning/developing skills } \\
\text { (cost) results in healthier eating (benefit) } \\
\text { when new skills are used. }\end{array}$ & $\begin{array}{l}\text { Supermarket } \\
\text { Garden centre }\end{array}$ & $\begin{array}{l}\text { Event (Grower competition) } \\
\text { Cooking demonstrations } \\
\text { Food tastings }\end{array}$ & $\begin{array}{l}\text { Local garden gurus } \\
\text { Chefs }\end{array}$ & $\begin{array}{l}\text { Displays } \\
\text { Information } \\
\text { Blogs } \\
\text { Demonstrations }\end{array}$ & $\begin{array}{l}\text { Hero plant/vegetable profiled monthl } \\
\text { Lessons (how to grow) at Garden Cel } \\
\text { cooking demonstrations (and tastings } \\
\text { supermarket showing how to use it in } \\
\text { meals }\end{array}$ \\
\hline $\begin{array}{l}\text { Cut the Crap } \\
\text { at the } \\
\text { Checkout } \\
\text { (Group 2.2) }\end{array}$ & $\begin{array}{l}\text { Lolly-free checkout } \\
\text { Alternative checkout } \\
\text { items }\end{array}$ & $\begin{array}{l}\text { Small effort needed to locate lolly-free } \\
\text { checkout within store (cost). Lolly } \\
\text { temptation is reduced (benefit). Attractive } \\
\text { items displayed at checkout (benefit). }\end{array}$ & Supermarket & Communication (checkout) & $\begin{array}{l}\text { Supermarket } \\
\text { management }\end{array}$ & $\begin{array}{l}\text { Lolly-free checkouts } \\
\text { Checkouts with other } \\
\text { items }\end{array}$ & $\begin{array}{l}\text { Unhealthy foods removed from checl } \\
\text { replaced with fruit, nuts, stationary. K } \\
\text { entertainment (mounted iPad/colouri } \\
\text { station) provided. }\end{array}$ \\
\hline $\begin{array}{l}\text { Asian Food } \\
\text { Experience } \\
\text { (Group 2.3) }\end{array}$ & $\begin{array}{l}\text { Asian food ingredients } \\
\text { Cooking demonstrations }\end{array}$ & $\begin{array}{l}\text { Time spent learning/developing skills } \\
\text { (cost) results in healthier eating (benefit) } \\
\text { when new skills are used. Reduced travel } \\
\text { is needed to obtain exotic ingredients } \\
\text { (benefit). }\end{array}$ & Supermarket & $\begin{array}{l}\text { Advertising (coming themes) } \\
\text { Cooking demonstrations } \\
\text { Food displays }\end{array}$ & Local chefs & $\begin{array}{l}\text { Pop-up store/counter } \\
\text { Displays and } \\
\text { demonstrations }\end{array}$ & $\begin{array}{l}\text { Pop-up store with rolling Asian them } \\
\text { (vegetable rich cuisines) in supermar } \\
\text { Local chefs conduct food demonstrat } \\
\text { in-store, all ingredients displayed tog }\end{array}$ \\
\hline $\begin{array}{l}\text { Eat Your Way } \\
\text { to Fitness } \\
\text { (Group 1.1) }\end{array}$ & $\begin{array}{l}\text { Fruits and vegetables } \\
\text { Rewards scheme }\end{array}$ & $\begin{array}{l}\text { Spending on } \mathrm{F} \& \mathrm{~V} \text { (cost) returns sports } \\
\text { equipment vouchers (benefit). F\&V } \\
\text { purchases (cost) create healthier eating } \\
\text { (benefit) and increased fitness (benefit). }\end{array}$ & $\begin{array}{l}\text { Supermarket } \\
\text { Sports store }\end{array}$ & Reward program & None suggested & Reward vouchers & $\begin{array}{l}\text { Spending } \$ 100 \text { on } \mathrm{F} \& \mathrm{~V} \text { to receive } \$ 1 \\
\text { voucher for sports equipment. }\end{array}$ \\
\hline $\begin{array}{l}\text { Healthy } \\
\text { Dollars } \\
\text { (Group 3.3) }\end{array}$ & $\begin{array}{l}\text { Eatable plants } \\
\text { Healthy foods } \\
\text { Sports equipment } \\
\text { Rewards scheme }\end{array}$ & $\begin{array}{l}\text { Spending on health products (cost) returns } \\
\text { rewards that can be spent on healthy } \\
\text { products (benefit). }\end{array}$ & $\begin{array}{l}\text { Supermarket } \\
\text { Garden centre } \\
\text { Sports store }\end{array}$ & Reward program & Management & Membership & $\begin{array}{l}\text { Spending on healthy produce, plants, } \\
\text { sportswear recorded for conversion it } \\
\text { discounts on produce, exercise classe } \\
\text { gym memberships, or free meal at the } \\
\text { from the healthy menu. }\end{array}$ \\
\hline $\begin{array}{l}\text { Be Active } \\
\text { While } \\
\text { Shopping } \\
\text { (Group 1.2) }\end{array}$ & $\begin{array}{l}\text { Healthy foods } \\
\text { Healthy policy } \\
\text { Discount scheme } \\
\text { Improved pedestrian and } \\
\text { cycling access }\end{array}$ & $\begin{array}{l}\text { Spending on healthy foods (cost) is } \\
\text { reduced (benefit). Effort walking and } \\
\text { cycling (cost) is easier (benefit) which } \\
\text { results in increased fitness (benefit). }\end{array}$ & $\begin{array}{l}\text { Supermarket } \\
\text { Common space }\end{array}$ & Event (Family fun day) & $\begin{array}{l}\text { Management } \\
\text { Community council }\end{array}$ & $\begin{array}{l}\text { Bike racks \& paths } \\
\text { Footpaths \& entrances } \\
\text { Water fountains }\end{array}$ & $\begin{array}{l}\text { Improved facilities to allow people to } \\
\text { walk/cycle to shops. Water fountains } \\
\text { encourage people to drink water inste } \\
\text { sugary drinks. Healthy policy to ensu } \\
\text { that events provide healthy food. } \\
\end{array}$ \\
\hline $\begin{array}{l}\text { Healthier You } \\
\text { (Group 3.1) }\end{array}$ & $\begin{array}{l}\text { Healthy products } \\
\text { (in-season/organic) } \\
\text { Reward/discount scheme }\end{array}$ & $\begin{array}{l}\text { Spending on F\&V (cost) returns vouchers } \\
\text { for fitness classes (benefit). Spending on } \\
\text { healthy foods (cost) is reduced (benefit). }\end{array}$ & Supermarket & $\begin{array}{l}\text { Sponsorships } \\
\text { Promotion }\end{array}$ & None suggested & Little to no detail & $\begin{array}{l}\text { Scheme to record spending on health } \\
\text { produce for conversion into exercise } \\
\text { classes, discount gym memberships. }\end{array}$ \\
\hline $\begin{array}{l}\text { Living my } \\
\text { Best Life } \\
\text { (Group 4.2) }\end{array}$ & $\begin{array}{l}\text { Reward/discount scheme } \\
\text { Cooking demonstrations } \\
\text { Shopping tours } \\
\text { Food displays } \\
\text { Recipe cards }\end{array}$ & $\begin{array}{l}\text { Spending on health products (cost) returns } \\
\text { rewards to be spent on healthy products } \\
\text { (benefit). Spending on healthy foods (cost) } \\
\text { is reduced (benefit). Time spent learning }\end{array}$ & $\begin{array}{l}\text { Supermarket } \\
\text { Garden centre } \\
\text { Sports store }\end{array}$ & $\begin{array}{l}\text { Cooking demonstrations } \\
\text { Food displays }\end{array}$ & None suggested & $\begin{array}{l}\text { Displays } \\
\text { Cooking } \\
\text { demonstrations } \\
\text { Recipe cards }\end{array}$ & $\begin{array}{l}\text { Reward program with weekly focuse } \\
\text { topics (kids cooking, exercise, goal s } \\
\text { healthy lifestyle). Discounts for mem } \\
\text { on healthy foods, gym membership, s }\end{array}$ \\
\hline
\end{tabular}




\begin{tabular}{|c|c|c|c|c|c|c|}
\hline & & $\begin{array}{l}\text { skills (cost) results in healthier eating } \\
\text { (benefit) when new skills are used. }\end{array}$ & & & & \\
\hline $\begin{array}{l}\text { A Healthy } \\
\text { Choice } \\
\text { Program * }\end{array}$ & $\begin{array}{l}\text { Fruits and vegetables } \\
\text { Healthy foods } \\
\text { Cooking demonstrations } \\
\text { Shopping tours } \\
\text { Recipe cards }\end{array}$ & $\begin{array}{l}\text { Time finding healthy food (cost) is reduced } \\
\text { (benefit) } \\
\text { Time spent learning/developing skills } \\
\text { (cost) results in healthier eating (benefit) } \\
\text { when new skills are used. }\end{array}$ & Supermarket & $\begin{array}{l}\text { Cooking demonstrations } \\
\text { Tastings (at demonstrations) } \\
\text { Communication/Advertising } \\
\text { Themes for communication } \\
\text { and demonstrations were: } \\
\text { Fresh, seasonal, local } \\
\text { produce. } \\
\text { Tasty, quick, easy dishes. }\end{array}$ & $\begin{array}{l}\text { Local dieticians } \\
\text { Supermarket } \\
\text { management } \\
\text { Chef (role performed } \\
\text { by dietician) }\end{array}$ & $\begin{array}{l}\text { Demonstrations } \\
\text { Recipe cards } \\
\text { Signage (in-store) } \\
\text { Information } \\
\text { Blogs } \\
\text { Displays }\end{array}$ \\
\hline
\end{tabular}

clothing, and plants. Reward from bo when goal reached.

Labelling/signage to assist consumers find healthy foods in store. Periodic cooking demonstrations to develop ne skills. Periodic label reading tours to information skills. Widespread media communicating benefits of tasty healt produce, and products.

* Rewards and discount schemes were not considered feasible by the management team for this version of the progra 
For product and services, participants emphasised healthy products (often fruit and vegetables) in their programmes. Supporting products and services included signage, reward schemes, tours, displays, and cooking demonstrations. For example, Market Day included an in-store market experience with several demonstrations preparing meals using fresh produce. This was supplemented with information and 'meal packs' containing all of the ingredients to assist shoppers in purchasing and preparing meals. Some participants proposed programmes that included modifications to facilities, such as water fountains and walking paths, or connected supermarket products (produce) with products and services in other stores such as the garden centre.

For price, despite a preference for discounts in the review of previous strategies, participants had realistic expectations that fresh and healthier products may be more expensive than those with a long shelf-life or less healthy ingredients. Their expectations involved competitive or appealing offers, rather than just 'cheap' ones. For example, Healthy Dollars presented a rewards scheme where shoppers earn points for spending on healthier items (i.e., fresh fruits and vegetables) and use the points as discounts on sporting equipment or gym membership run by the same company as the supermarket. Another group independently proposed a scheme where shoppers obtain a $\$ 10$ voucher for sporting equipment/clothes for every $\$ 100$ dollars spent on fresh fruits and vegetables.

Promotion aspects focussed on events, displays, demonstrations, and advertising to inform and engage the shopping community with the programme features. These strategies were apparent as physical evidence across a variety of media, from blogs, articles, and recipe cards in-store, in local print and social media, to information in-store, such as signage, and labels on products. For example, Pointing in the right direction presented suggestions for navigation signs in a supermarket. Other signage and layout modifications could make it easier for shoppers to get to fresh fruit and vegetables areas.

The people aspect was less prevalent in the co-design discussions, with few mentions covering the need for staff to be knowledgeable about the health aspects of their product range and opportunities to bring other experts to the retail environment (i.e., dieticians, local chefs) to enhance the experiential aspect of shopping.

The process aspect articulated the desire for enhanced in-store experiences as a way to better understand where the food comes from, how to grow it, and how to use it in cooking. This was particularly prominent in a very novel idea of purpose-created displays that celebrate a 'hero ingredient' across its lifecycle showing consumers how to grow it (gardening supplies and tips), and how to choose, correctly store, and cook with it. Several programme ideas included cooking demonstrations, while others suggested food label-reading workshops conducted by local dieticians as a way to educate shoppers on how to make healthier food choices. Participants proposed organising events with the farm-market feel, providing more experiential opportunities (i.e., meet the grower, free sampling), and promoting food with local provenance as part of a broader programme.

In summary, the suggestions from all groups centred around six key themes: 1) increase the availability of foods (i.e., healthier, seasonal, and local options); 2) increase prominence of foods by signposting them for easier location in a supermarket environment; 3 ) provide more information and education around healthier choices from reputable sources (i.e., dieticians) through out-of-store (media, blogs, etc.) and in-store workshops; 4) offer more hands-on in- 
store experience (i.e., cooking demonstrations) where shoppers can sample and see how to cook with healthier foods; 5) develop a financial reward programme to encourage healthier choices; and 6) consider modifying the entire shopping centre environment to promote more opportunities for incidental physical activity (i.e., biking, walking, water fountains). These six themes were evident in 'mud maps', but also aligned with findings for the most liked previous programme ideas.

\section{Consumer vs staff: a feasibility assessment}

An important and novel aspect of this research (often overlooked in past studies) is consideration of the staff perspective. Staff offer much-needed expertise in the feasibility aspect of any new programme ideas. Beyond that, involving staff in all steps of design idea generation and development ensures staff 'buy-in', championing, and future commitment to the project throughout the testing and implementation stages.

Staff views were used in two ways. Firstly, invited staff took part in their own co-design workshop, following the same protocol as consumers and culminating in the generation of their own ideas and four new 'mud maps'. Core themes (described above) were very similar for both consumers and staff. Both covered the need for healthier foods to be more available, more prominent, and promoted through a range of engaging in-store experiences and out-of-store communications. Zooming in on the differences, staff had more detailed, operational suggestions for how their ideas could be implemented. This was not to say that consumers could not envisage practical or workable solutions: Consumers had very realistic expectations for their ideas (i.e., no one asked for free food or unreasonable discounts). However, staff were able to elaborate on their ideas to include aspects relating to implementation that consumers did not consider or convey in their mud maps.

Secondly, a wider selection of staff reviewed all the 'mud maps' generated by consumer groups. Ideas were positioned along the corridor in staff offices. Staff voted on ideas they liked the most and thought to be feasible with colourful sticky tags. This indicated which ideas should be given more consideration and would have better chances of gaining staff support. The ideas that attracted more votes included: mini pop-up displays featuring a food item and showing how to grow and cook with it in cooking demonstrations, healthier checkouts, more signage in-store to facilitate finding healthier options, and the installation of bike racks and water fountains.

\section{Summary of Study 1}

The co-design workshops developed a broad range of ideas on how to increase food well-being in a supermarket setting through programmes that create in-store food experiences and broader community engagement activities with the potential to increase healthier food choices. A crucial novelty of the current study was the formal involvement of staff in the ideation and feasibility testing. Although staff ideas were created independently from consumers, they exhibited similarity, while staff voting on consumer ideas also approved of the suitability and feasibility of in-store experiences and many of the other suggested programme activities. 


\section{Study 2: Programme development, implementation, and evaluation}

Study 2 addressed the second research objective to evaluate the effectiveness of a co-designed programme in terms of influencing healthfulness of choices in a real supermarket.

\section{Programme description}

Co-design findings were collated in a technical report (with illustrated 'mud maps') and presented to supermarket management for evaluation and consideration of feasibility. An accredited and practicing dietician was engaged to ensure credible translation between evidence-based knowledge of healthy choices and the programme elements as suggested by consumers. A professional design agency was briefed to create appealing marketing collateral for the programme.

This programme was branded 'A Healthy Choice' and contained many strategies suggested by consumers, as shown in Table 3 (last row). Interestingly, the broader ideas included strategies found to be effective in previous supermarket programmes (e.g., van't Riet, 2013, Escaron et al., 2013, Liberato et al., 2014). The programme addressed all seven Ps except for price. Discounts on commercial products within the supermarket were deemed not feasible in this project due to restrictions on funding rules when financed through a competitive grant by a local government.

The product and physical evidence dimensions were addressed by the dietician who identified a total of 175 healthy products from frequently bought categories. These products were low sugar, low total fat, low saturated fat, low sodium/salt, and high fibre. They were then identified in-store using shelf-talkers showing the 'A Healthy Choice' logo and a verbal description of why this product is a healthier option (see Figure 3). Shelf-talkers were placed on the selected products for the whole duration of the programme. It is important to note that there were no discounts, or any financial incentives offered on these products (beyond those that were part of the normal commercial promotion schedule on these and other products). The place dimension was addressed by offering 'A Healthy Choice' labelled products more prominent shelf space in the supermarket (e.g., endcaps and feature displays), which have been shown to increase product visibility and choice (Caruso et al., 2018, Tan et al., 2018).

The promotion dimension was addressed through a media campaign comprising regular articles in local print media and a Facebook blog, which covered a range of topics including: correct food label reading, benefits of vegetables, healthy lunch boxes, benefits of fish and seafood, healthy fats, ideas for healthy breakfasts, platters, snacks, and meal planning.

The people dimension was represented through cooking demonstrations conducted by the local dietician in-person in-store featuring local and seasonal healthy produce. Interactions through social media with the dietician also provided opportunities for consumers to engage with people knowledgeable about healthy food choices. Finally, the process dimension was executed through the management of the programme and the very strong buy-in and feel of ownership that retail staff felt towards the programme as a result of the co-design process.

In relation to the food well-being framework (Block et al., 2011), all five domains were reflected in the programme design. For example, food availability was addressed by expanding the range of healthier products on shelves. Food literacy was addressed through the media and 
education campaign and cooking demonstrations. Food socialisation was achieved through workshops and other community events linked to the programme. Food marketing was reflected through the media campaign and the shelf labels. Finally, food policy on the retailer and community levels was covered by raising overall awareness of the importance of healthier food choices, which then led to programmes and campaigns run by management that favoured healthier options (e.g., serving water instead of soft drinks at events).

\section{Figure 3. 'A Healthy Choice' logo and shelf-talkers}
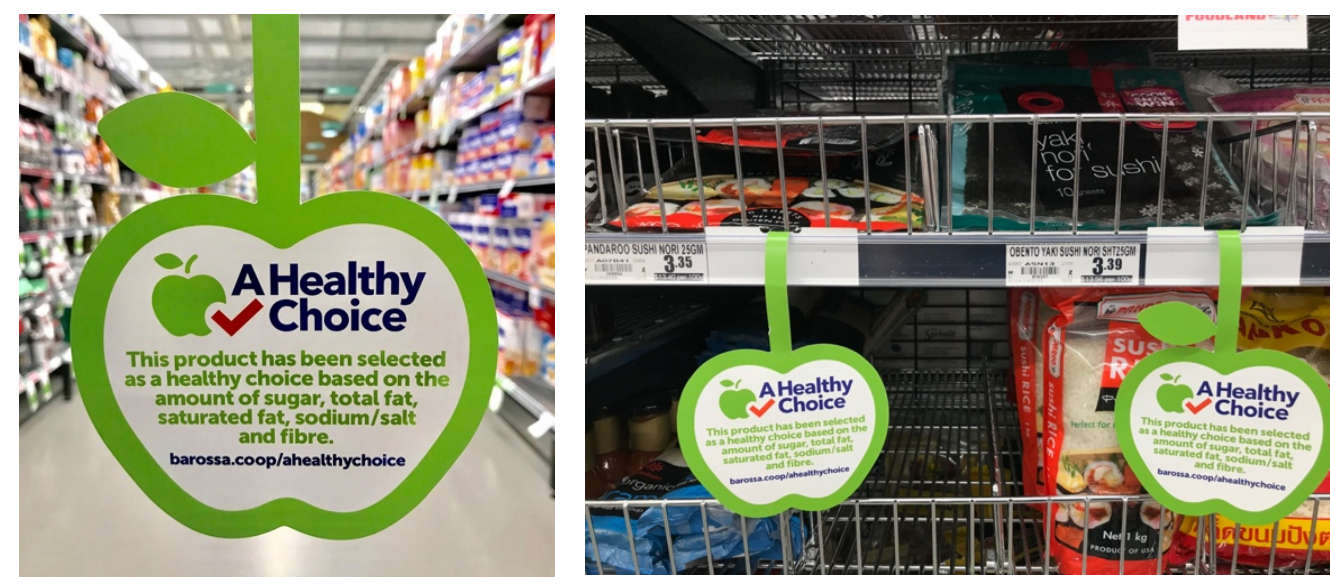

\section{Programme Evaluation - Awareness and satisfaction}

Programme evaluation covered two dimensions: 1) consumer awareness and satisfaction with the programme and 2) changes in sales of promoted healthier products in the supermarket.

A short online survey was developed and distributed to members of the supermarket loyalty scheme list through an electronic database a week before the programme started $(n=54$, baseline) and again upon its completion ( $\mathrm{n}=125$, follow-up). Survey participants were primarily supermarket members (95\% before, $98 \%$ after), females ( $75 \%$ before, $67 \%$ after), having at least one child in the household ( $86 \%$ before, $83 \%$ after), while median age bracket was $46-55$ years in both waves. This profile is broadly representative of the people in households with primary responsibility for shopping and cooking.

At the end of the programme, the unprompted awareness of the entire programme was $31 \%$. When prompted for specific components of the programme, $74 \%$ were aware of cooking demonstrations, $65 \%$ of shelf-talkers, $53 \%$ of label-reading workshops, $40 \%$ of articles in local press, and $20 \%$ of weekly posts/blogs. This suggests a high level of community awareness of the programme. Furthermore, $45 \%$ claimed that their knowledge of healthy living choices had improved thanks to the programme. In terms of participation rates, $55 \%$ claimed to have bought items with shelf-talkers, $51 \%$ read articles in the local press, $40 \%$ read articles on the supermarket website, $36 \%$ read the newsletter, $26 \%$ read blogs, $17 \%$ attended cooking demonstrations, and $11 \%$ attended label-reading workshops.

Of those who answered the survey and also attended the label-reading workshops $(n=6), 100 \%$ were satisfied or very satisfied. Similarly, of survey respondents who also attended cooking workshops $(\mathrm{n}=7), 72 \%$ were satisfied and very satisfied. Qualitative feedback through social media on the programme was very positive, including comments such as 'great initiative', 
'thanks for these, made a choice tonight based on the shelf-talkers', 'love seeing these [shelftalkers] all around [the supermarket]'.

Fresh fruits and vegetables were not directly promoted with shelf-talkers (only through cooking workshops and in the media campaigns), hence their possible uplift was not captured in the sales data. Nevertheless, to measure a possible increase in consumption, the before-after survey included two questions about consumption of fresh fruits and vegetables (separately). The question asked: "How many times do you typically each vegetable (for example, salad, greens, broccoli, spinach), in one day of a typical week?' A similar question was asked about fruits. Mean consumption showed an increasing trend from 4.43 (2.37) to 4.71 (2.54) for vegetables, and from $3.78(2.38)$ to $3.84(2.43)$ for fruits. None of these results are statistically significant $(\mathrm{p}=0.32$ and 0.83 , respectively), possibly due to small sample sizes.

\section{Programme Evaluation - Sales of promoted healthier products in the supermarket}

\section{Data description}

The analysis covered weeks 27 to 39 in the annual calendar. Over that 13-week period, customers made on average in the whole supermarket 17,346 shopping trips and bought 176,434 items per week, which is typical for a medium-size Australian supermarket. In total, there were 175 Stock Keeping Units (hereafter SKUs) identified with the shelf-talker 'A Healthy Choice'. These SKUs came from 16 different product categories (Table 5). In total, there were 19,360 items of these SKUs sold during the programme. Sales data were aggregated on a weekly basis to control for variability in sales levels across weekdays (a known trend in supermarket data).

The analysis compared sales (in units) of SKUs identified with the shelf-talkers with a control group that was the unit sales of the same SKUs sold in the period (weeks 27 to 39) in 2018. Calendar periods were matched between programme and control conditions to account for seasonal trends (another known bias). Sales of promoted SKUs were compared with sales of all other SKUs in the same product categories (e.g., breakfast foods or yoghurt) without shelftalkers. Category-level analysis was needed to control for variability in sales levels between more and less popular product categories, and variation in the total number of SKUs in the category and the number of SKUs identified with shelf-talkers.

To ensure an unbiased comparison, only SKUs that were available during each week of the 13week programme period in both 2019 and 2018 were included in the analysis. There were 58 such SKUs, totalling 13,214 units in sales during the programme, accounting for $68 \%$ of all sales of the 175 SKUs that participated in 'A Healthy Choice'.

The hypothesis was that SKUs identified with shelf-talkers (highlighting health benefits) would experience an increase in the number of items sold. The analysis employed a two-way ANOVA, where the dependent variable was the average number of items sold per week per SKU. The independent factors were: Year (2018 or 2019), 'A Healthy Choice' programme participation (True or False), and an interaction between these two factors. Statistical significance of the interaction term would indicate that the change in the sales was due to 'A Healthy Choice' programme, and not year-to-year sales variability or individual brands' popularity (both general trends). 


\section{Results}

Firstly, a descriptive analysis compared the overall sales in the entire supermarket with sales in 'A Healthy Choice' SKUs during 2019 and 2018. The results show that the overall supermarket sales in 2019 were $2.9 \%$ lower than in 2018 during the same period (2018 $2,360,290 ; 2019-2,293,644$ items over 13 weeks). This is an important general trend that could influence the results in the focal period. Yet the sales of the 58 SKUs that participated in the programme and available in both years were 1.0\% higher in 2019 compared to 2018 (2018 - 13,084; 2019 - 13,214 items over 13 weeks). This suggests that, despite a general declining trend in the whole supermarket, the sales of the promoted items were $3.9 \%$ higher than in the rest of the supermarket (a $2.9 \%$ decline in whole supermarket vs a $1 \%$ increase in promoted SKUs).

Category-level analysis (Table 5) indicates that, out of 16 product categories, five (milk and milk drinks, salad, ready meals, baked in-store bread, and miscellaneous meat) demonstrated a statistically significant effect of 'A Healthy Choice' at the 5\% significance level, and one category (health foods) at the 10\% significance level. All but one of these categories (bread baked in-store) demonstrated positive relative change in sales for the promoted SKUs.

Table 4. Change in average weekly unit sales of 'A Healthy Choice' SKUs and Product Category SKUs, 2018 to 2019

\begin{tabular}{|c|c|c|c|c|c|c|c|c|c|}
\hline & 'A Health & Choice' & & Other $S I$ & s in th & ategory & & \multirow{2}{*}{\multicolumn{2}{|c|}{ P-value }} \\
\hline Category Name & N SKUs & $\begin{array}{l}\text { Ave. } \\
\text { units }\end{array}$ & $\Delta 2018$ & N SKUs & $\begin{array}{l}\text { Ave. } \\
\text { units }\end{array}$ & $\Delta 2018$ & $\begin{array}{c}\text { Compare } \\
\text { sales } \\
\text { change: } \\
\text { 'A H Choice' } \\
\text { vs other }\end{array}$ & & \\
\hline $\begin{array}{l}\text { Bread in-store } \\
\text { baked }\end{array}$ & 1 & 8.2 & $-55.3 \%$ & 86 & 24.7 & $27.8 \%$ & $-83.1 \%$ & 0.00 & $* *$ \\
\hline Ready meals & 2 & 11.0 & $53.8 \%$ & 329 & 7.7 & $-11.1 \%$ & $64.9 \%$ & 0.00 & $* *$ \\
\hline $\begin{array}{l}\text { Milk and milk } \\
\text { drinks }\end{array}$ & 9 & 15.9 & $3.2 \%$ & 262 & 24.4 & $-11.6 \%$ & $14.9 \%$ & 0.01 & $* *$ \\
\hline Salads & 5 & 13.3 & $13.7 \%$ & 99 & 22.6 & $-7.3 \%$ & $20.9 \%$ & 0.01 & $* *$ \\
\hline $\begin{array}{l}\text { Miscellaneous } \\
\text { meat }\end{array}$ & 1 & 5.5 & $-15.3 \%$ & 71 & 18.4 & $-20.1 \%$ & $4.8 \%$ & 0.04 & $* *$ \\
\hline Health foods & 2 & 7.9 & $26.4 \%$ & 503 & 2.7 & $-3.4 \%$ & $29.8 \%$ & 0.09 & $*$ \\
\hline Breakfast foods & 7 & 40.2 & $10.2 \%$ & 363 & 7.3 & $-11.6 \%$ & $21.8 \%$ & 0.15 & \\
\hline $\begin{array}{l}\text { Imported } \\
\text { grocery lines }\end{array}$ & 1 & 8.5 & $-23.1 \%$ & 121 & 4.7 & $-9.7 \%$ & $-13.4 \%$ & 0.16 & \\
\hline $\begin{array}{l}\text { Pasta and } \\
\text { tomato paste }\end{array}$ & 2 & 6.5 & $0.0 \%$ & 259 & 6.4 & $-10.1 \%$ & $10.1 \%$ & 0.39 & \\
\hline Cheese & 5 & 7.9 & $-7.7 \%$ & 195 & 12.0 & $-10.2 \%$ & $2.4 \%$ & 0.40 & \\
\hline Soy products & 2 & 5.2 & $15.3 \%$ & 19 & 3.3 & $12.3 \%$ & $3.0 \%$ & 0.56 & \\
\hline $\begin{array}{l}\text { Tip } \\
\text { top/buttercup }\end{array}$ & 9 & 25.6 & $-4.7 \%$ & 127 & 47.1 & $-3.5 \%$ & $-1.2 \%$ & 0.56 & \\
\hline
\end{tabular}




\begin{tabular}{|l|c|c|c|c|c|c|c|c|}
$\begin{array}{l}\text { Milks - } \\
\text { powdered and } \\
\text { canned }\end{array}$ & 1 & 24.9 & $-15.4 \%$ & 118 & 22.2 & $-5.3 \%$ & $-10.1 \%$ & 0.56 \\
\hline Dips & 2 & 6.8 & $3.5 \%$ & 51 & 3.8 & $-4.4 \%$ & $7.9 \%$ & 0.66 \\
\hline Yoghurt & 5 & 13.4 & $-4.6 \%$ & 183 & 5.6 & $-8.9 \%$ & $4.3 \%$ & 0.90 \\
\hline Biscuits & 4 & 16.5 & $-7.5 \%$ & 410 & 15.5 & $-7.4 \%$ & $-0.1 \%$ & 0.94 \\
\hline
\end{tabular}

* statistical significance at the 10\% level; ** statistical significance at the 5\% level; $n$. s. means statistically non-significant. $\Delta \mathbf{2 0 1 8}$ column shows a percentage difference compared to sales in 2018.

Sales in the ready meals category showed a very strong interaction between annual changes and programme participation. 'A Healthy Choice' SKUs showed 53.8\% sales growth (Figure 4, left, green line), while the rest of the category decreased by $11.1 \%$ (Figure 4 , left, red line). Sales of 'A Healthy Choice' SKUs in the milk and milk drinks category increased by $3.2 \%$ from 2018 (Figure 4, right, a green line), while the rest of the category's SKUs declined by $11.6 \%$ (Figure 4, right, red line). These results, together with those in three other categories (salads, miscellaneous meats and health foods), offer evidence of the significant and positive effect of 'A Healthy Choice' on sales in those categories.

Figure 4: Interaction effects between annual changes (2018-2019) and SKUs participation in 'A Healthy Choice': ready meals (left), milk and milk products (right).
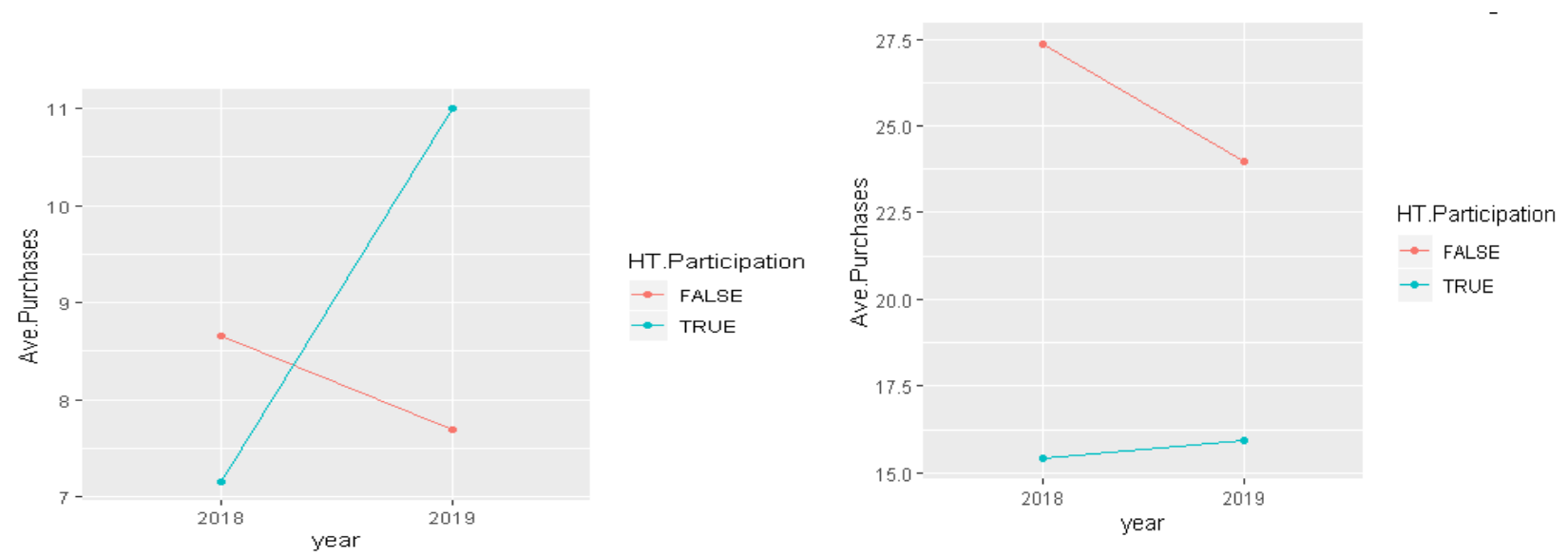

In the biscuits category, Figure 5 (left) reveals no interaction between model factors, shown by parallel lines and an almost identical 7.4-7.5\% drop in sales for participating SKUs and for the remainder of the category. For the soy category, Figure 5 (right) illustrates a pattern of positive interaction between independent factors: SKUs with shelf-talkers grew more (15.3\%) than the remainder of that category $(12.3 \%)$. However, this observed effect was not statistically significant due to a small sample size and high variability in the sales data in this category; hence, the results are not conclusive. These findings suggest that there is not enough evidence for an effect of 'A Healthy Choice' on sales in those categories. 
Figure 5. Interaction effects between annual changes (2018-2019) and SKUs participation in 'A Healthy Choice': biscuits (left), and soy products (right).
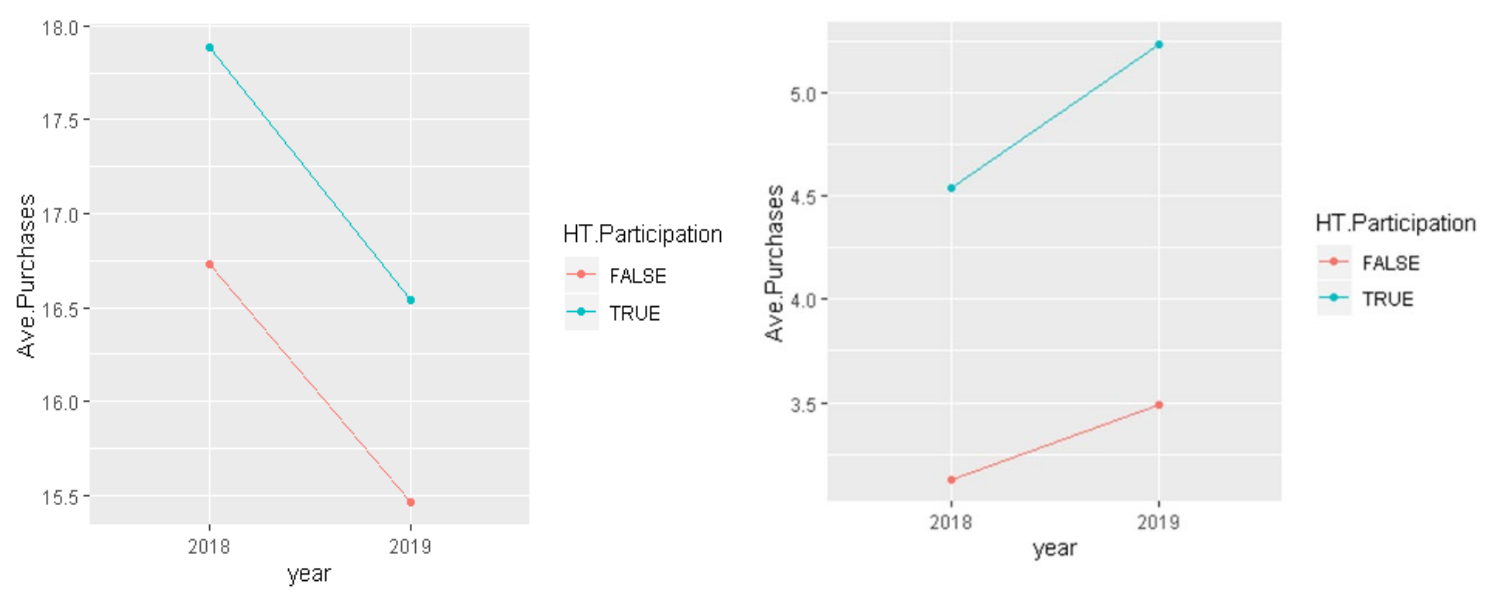

Overall, across 16 product categories examined, the results in 10 did not reach statistical significance due to large variability in those categories, which reduced statistical power. For some of the 10 categories, the magnitude of change was meaningful and in the right direction (but n.s. due to sample/size variability), while in the others there was no difference or even a negative trend (but also n.s.).

\section{Discussion and conclusions}

\section{Results overview}

This research examined the process of co-design and evaluated a programme that aimed to positively influence consumer food well-being within a supermarket setting. Using a design thinking approach to generate programme ideas, together with a survey and sales data to evaluate the outcomes, the study demonstrated the potential of this approach to underpin design and implementation of programmes with real-world impact. Study 1 presented the results of the co-design workshops with consumers and staff, which led to the creation of 15 new ideas for a programme design. Based on these findings, a supermarket's management developed a programme called 'A Healthy Choice', which included a wide range of activities to inform the community about benefits of healthy food choices and skills-building workshops to empower consumers in making those choices. At the final stage, shelf-talkers were placed on 175 supermarkets items across 16 product categories deemed healthier choices by a dietician, according to the levels of sugar, total/saturated fat, salt, and fibre.

Study 1 (co-design workshops) revealed that the involvement of the end-consumers and staff in the co-design of a programme provided great breadth and depth of new ideas about how to encourage healthier choices in a retail setting. Strong themes that emerged were ideas around modifying the supermarket environment to make it easier for consumers to identify healthier products (with some form of signage). Consumers also expressed a need for a community-wide inclusive campaign to educate and encourage healthier choices. The desire for deeper food experiences (cooking demonstrations, feature displays, skills building workshops) was also a common theme in participants' views. A suggestion for some form of financial reward for healthier purchases was also observed. 
Study 2 (a community-wide programme and supermarket on-shelf intervention) showed that, after four months, the programme achieved a high level of consumer awareness overall $(31 \%$ unprompted recall) and of its specific activities (53\%-74\%). Those who took part in the workshops were largely satisfied or very satisfied with their experience and a large proportion of community $(55 \%)$ reported buying products promoted with the shelf-talkers. The analysis of sales data, however, showed somewhat mixed results. Of the 16 categories with products signposted with 'A Healthy Choice' shelf-talkers, four had a significant and positive effect of the programme. An additional 10 also trended in the positive direction, although not statistically significant due to large variability in sales data. The rest were also non-significant, except for one, showing a trend in the opposite direction. This could be the result of a preference towards more 'local' options, away from healthier but imported options (soy products), and towards fresher whole foods (fresh milk and milk drinks), away from highly processed foods (milk powder/can).

Taken together, these results present evidence that consumers and staff were able to make a substantial and important contribution towards designing a food well-being programme and, among staff, and then champion it to implementation. Consumers were very supportive of the programme, although the sales data are very complex. This made it problematic to cleanly separate out just the effect of the programme from many other factors in the real-world environment, which are necessarily present in a real-world setting such as a supermarket.

\section{Contributions to theory and practice}

\section{Contributions to food well-being}

This study contributes to the food well-being literature by conceptualising the path to food well-being as a collaborative venture to be co-created between consumers and other societal actors (in this case, food providers). A co-created and collaborative effort towards food wellbeing, as undertaken in this study, is aligned with the holistic and integrated nature of the concept (Block et al., 2011). Furthermore, it underscores the importance of creating partnerships among stakeholders who are proactive actors, not just passive compliers. Traditional notions of well-being consider it a positive 'state' to be reached, whereas consumers may derive well-being from engagement in the experience of striving towards something better (Mugel et al., 2019). Through the co-design process, consumers and staff collectively expressed a desire for strategies within each food well-being domain: food availability (healthy products), food literacy (labelling), food marketing (pricing and promotions), food socialisation (media and events), and food policy (restrictions on unhealthy products). Some of the most imaginative suggestions placed emphasis on the social and experiential nature of food purchasing, preparation, and consumption, demonstrating the importance of food socialisation as part of food well-being (Batat et al., 2019).

Relating the results back to the food well-being framework, this programme has addressed five domains: food availability, food literacy, food socialisation, food marketing, and food policy (Block et al., 2011). The positive effect on purchases is one tangible measure of food wellbeing (assuming that purchases equate to consumption of healthier products). In terms of the goals of food well-being, the programme was consumer oriented, positive, and took a holistic view of progressing food well-being. Social and service marketers and programme developers can learn from this approach and extend future programmes to measure not only purchases of healthier foods, but also positive indicators of behavioural changes in food consumption, and 
attitudinal changes towards community and family socialisation and connectedness through food. Future programmes could include strategies that extend and support those placed in the supermarket into family and consumer settings to increase the positive impact on food wellbeing.

This study contributes empirical evidence that a food well-being programme in a supermarket can deliver benefit to the community at large and to each consumer. The significant role that supermarkets play in modern societies, as places of food provisioning and meal inspirations, warrant greater efforts to seek collaborations between health practitioners and supermarket management. Supermarkets can deliver scale (in terms of the number of people influenced), relevant context (since this is where people make food choices), and places of socialisation and community unity around food.

\section{Contributions to design thinking and co-design}

This study supports active involvement of end users to build effective service solutions (Melton and Hartline, 2015), but also ensures that wider stakeholder views and input are carefully considered in the co-creation process. To date, relatively few insights are available on the involvement of multiple stakeholder groups and their respective contribution to the creation of new services (Ostrom et al., 2015).

This study contributes to the design thinking (DT) literature by showcasing how a seven-step co-design framework can contribute to a richer and more rigorous DT process. This work answers direct calls by recent systematic reviews in DT highlighting the need for more "conceptual clarity and methodologically robust empirical studies in design thinking to avoid the fate of other management concepts in which research disintegrated into a collection of ad hoc, atheoretical and non-cumulative studies (Micheli et al., 2019, p. 143). Specifically, codesign ensured that key stakeholder voices were heard and that deeper user insights can be produced by empowering the people who will ultimately be the recipients of the service solution.

Additionally, this research contributes significantly to the existing co-design and DT literature by demonstrating the actual implementation of a behaviour change campaign in a supermarket context. Thus far, most co-design studies show its value in the early stages of the DT process; however, evaluation of these co-designed solutions in terms of their effectiveness is lacking (Dietrich et al., 2017b, Durl et al., 2017, Hurley et al., 2018). Finally, and to the best of the authors' knowledge, this paper is also the first study that applies co-design and DT in a supermarket context, indicating their value for food-related research contexts.

\section{Contribution to supermarket programmes}

The key contribution of this work to the supermarket intervention literature is the recommendation to change the paradigm of engagement. The broader health promotion literature typically views supermarket management as 'enemies' of food well-being. After all, the prevalence of unhealthy foods in many supermarkets has been criticised for fuelling the obesity pandemic (Cohen and Babey, 2012). Using co-design and DT frameworks, we offer an example of stakeholders working together in close partnership to co-design and collaboratively implement a programme that promotes healthier choices. This demonstrates that a successful food well-being programme can deliver more than just public health and well-being goals, but 
also commercial outcomes. Indeed, the increase in sales in some categories observed in this research (with no financial loss due to discounts) increases the supermarket's 'bottom line'. Moreover, profit margins on healthier products and fresh fruits and vegetables (the healthiest of all foods) are often higher than staple packaged goods. Hence, promoting healthier products will help to improve the overall profits of a supermarket, while clearly increasing the food wellbeing of individual consumers and the local community. This in turn will create satisfied customers who enjoy coming back to shop at that retailer.

In terms of practical implications, this work illustrates the specific steps and tasks involved in the design, implementation, and evaluation of this programme. This provides a 'road map' for future researchers and health and retail practitioners to guide them through key decisions that need to be made collaboratively with all stakeholders. Further implications arise from the challenges experienced during analysis of sales data. For example, an evaluation plan should be designed at the same time as the whole programme to ensure that more complete data is available for analysis. One limitation of the current work was that about $40 \%$ of the SKUs that participated in 'A Healthy Choice' did not have baseline sales data from a previous year (due to unavailability). This reflects the reality of the marketplace that contains a high turn-around of new and old SKUs. Future evaluations would need to consider how to include new SKUs in the evaluation, as it may be important to highlight these emerging products in a food well-being programme.

Another important aspect of sales data analysis is the need to account for as many variables as possible. This means having these variables in the data in the first place, and then incorporating them into the statistical models. This study used a strong design that controlled for variance in days of the week, seasonality, product category, and annual changes due to general and possibly global trends, including a decline in retail activity. This was aided by the availability of data to form a robust control group. Echoing the previous point, we recommend data extraction from a retail partner before the programme's implementation to enable a thorough examination that ensures the availability of all the above variables for analysis.

\section{Limitations and future research}

Given the real-world setting for this research, there were several innate limitations. The codesign process generated many more ideas than could be implemented, thus creating a strong 'pipeline' for future programmes. Despite the community-wide information campaign, there were lower rates of participation in early workshops, but later workshops were fully booked. We recommend that future programmes build stronger awareness of events at the earlier stages to ensure efficient use of programme resources.

Some residents suggested that shelf-talkers should be used to identify healthier options in more product categories. Indeed, the programme covered only 175 SKUs in a supermarket with $>25,000$ SKUs. Future programmes should cover more SKUs and product categories to guide more shoppers more often. Similarly, a different approach is needed to assist consumers with buying more fresh fruits and vegetables, where all products in the category are healthy, perhaps signage to direct shoppers to the whole area.

This programme lasted 13 weeks to allow for the longest possible examination of programme effects within the budget. Prior studies have looked at even longer programmes, suggesting that they tended to be more successful (van't Riet, 2013). However, shopper habituation to the 
shelf-talkers is a known factor that could reduce effectiveness over time. Therefore, we recommend running programme elements in several waves to re-fresh and revive shoppers' experiences, while ensuring strong continuity in the whole programme and fidelity to original objectives. Continuous or time series evaluation of each wave will provide insight into effects that are sustained or deteriorate over time.

Past literature shows that price discounts significantly influence sales levels several times more than any non-discounted promotions (Liberato et al., 2014). The budget for this programme did not allow for discounts on healthier items. This is likely to have limited the impact on sales. It also made it more difficult to determine the effect of the non-price promotional shelf-talkers, over and above the general noise in the sales data caused by the general trends (some of which were controlled for), as well as the effect of on-going commercial price discounts, which are a reality of any real-world supermarket environment. 


\section{References}

ADDIS, M. \& HOLBROOK, M. 2019. From food services to food experiences: Eating, wellbeing, and marketing. In: BATAT, W. (ed.) Food and Experiential Marketing. New York: Routledge.

BATAT, W., PETER, P. C., MOSCATO, E. M., CASTRO, I. A., CHAN, S., CHUGANI, S. \& MULDROW, A. 2019. The experiential pleasure of food: A savoring journey to food well-being. Journal of Business Research, 100, 392-399.

BIJMOLT, T. H. A., VAN HEERDE, H. J. \& PIETERS, R. G. M. 2005. New empirical generalizations on the determinants of price elasticity. Journal of Marketing Research, XLII, 141-156.

BLOCK, L. G., GRIER, S. A., CHILDERS, T. L., DAVIS, B., EBERT, J. E. J., KUMANYIKA, S., LACZNIAK, R. N., MACHIN, J. E., MOTLEY, C. M., PERACCHIO, L., PETTIGREW, S., SCOTT, M. \& BIESHAAR, M. N. G. V. 2011. From Nutrients to Nurturance: A Conceptual Introduction to Food Well-Being. Journal of Public Policy \& Marketing, 30, 5-13.

BRAUN, V. \& CLARKE, V. 2006. Using Thematic Analysis in Psychology. Qualitative Research in Psychology, 3, 77-101.

BRONFENBRENNER, U. 2005. Making Human Beings Human: Bioecological Perspectives on Human Development, Thousand Oaks, California, United States, Sage Publications.

BROWN, T. 2008. Design thinking. Harvard Business Review, 86, 84.

BROWN, T. 2009. Change By Design, New York, NY, United States, Harper Collins.

BUBLITZ, M. G., HANSEN, J., PERACCHIO, L. A. \& TUSSLER, S. 2019. Hunger and Food Well-Being: Advancing Research and Practice. Journal of Public Policy \& Marketing, 38, 136-153.

BUBLITZ, M. G., PERACCHIO, L. A., ANDREASEN, A. R., KEES, J., KIDWELL, B., MILLER, E. G., MOTLEY, C. M., PETER, P. C., RAJAGOPAL, P., SCOTT, M. L. \& VALLEN, B. 2013. Promoting positive change: Advancing the food well-being paradigm. Journal of Business Research, 66, 1211-1218.

CARUSO, W., CORSI, A. M., BOGOLOVEMA, S., COHEN, J., SHARP, A., LOCKSHIN, L. \& TAN, P. J. 2018. The Real Estate Value of Supermarket Endcaps: Why Location In-Store Matters. Journal of Advertising Research 58, 177-188.

COHEN, D. A. \& BABEY, S. H. 2012. Contextual influences on eating behaviours: Heuristic processing and dietary choices. Obesity Reviews, 13, 766-779.

DAVID, P., RUNDLE-THIELE, S., PANG, B., KNOX, K., PARKINSON, J. \& HUSSENOEDER, F. 2019. Engaging the Dog Owner Community in the Design of an Effective Koala Aversion Program. Social Marketing Quarterly, 25, 55-68.

DIETRICH, T., RUNDLE-THIELE, S. \& KUBACKI, K. 2017a. Segmentation in Social Marketing: Process, Methods and Application, Berlin/Heidelberg, Germany, Springer.

DIETRICH, T., TRISCHLER, J., SCHUSTER, L. \& RUNDLE-THIELE, S. 2017b. Codesigning services with vulnerable consumers. Journal of Service Theory and Practice, 27, 663-688.

DOMEGAN, C., COLLINS, K., STEAD, M., MCHUGH, P. \& HUGHES, T. 2013. Value co-creation in social marketing: Functional or fanciful? Journal of Social Marketing, $3,239-256$.

DURL, J., TRISCHLER, J. \& DIETRICH, T. 2017. Co-designing with young consumersreflections, challenges and benefits. Young Consumers, 18, 439-455. 
ELSBACH, K. D. \& STIGLIANI, I. 2018. Design Thinking and Organizational Culture: A Review and Framework for Future Research. Journal of Management, 44, 2274-2306.

ESCARON, A. L., MEINEN, A. M., NITZKE, S. A. \& MARTINEZ-DONATE, A. P. 2013. Supermarket and grocery store-based interventions to promote healthful food choices and eating practices: A systematic review. Preventing Chronic Disease, 10.

HOEK, J. \& JONES, S. C. 2011. Regulation, public health and social marketing: a behaviour change trinity. Journal of Social Marketing, 1, 32-44.

HOUGHTALING, B., SERRANO, E. L., KRAAK, V. I., HARDEN, S. M., DAVIS, G. C. \& MISYAK, S. A. 2019. A systematic review of factors that influence food store owner and manager decision making and ability or willingness to use choice architecture and marketing mix strategies to encourage healthy consumer purchases in the United States, 2005-2017. International Journal of Behavioral Nutrition and Physical Activity, 16, 5.

HURLEY, E., TRISCHLER, J. \& DIETRICH, T. 2018. Exploring the application of codesign to transformative service research. Journal of Services Marketing, 32, 715-727.

LIBERATO, S. C., BAILIE, R. \& BRIMBLECOMBE, J. 2014. Nutrition interventions at point-of-sale to encourage healthier food purchasing: A systematic review. $B M C$ public health, 14, 919-933.

LOCKWOOD, T. 2010. Design Thinking : Integrating Innovation, Customer Experience, and Brand Value, New York, United States, Skyhorse Publishing Company.

MELTON, H. \& HARTLINE, M. D. 2015. Customer and employee co-creation of radical service innovations. Journal of Services Marketing, 29, 112-123.

MICHELI, P., WILNER, S. J. S., BHATTI, S. H., MURA, M. \& BEVERLAND, M. B. 2019. Doing Design Thinking: Conceptual Review, Synthesis, and Research Agenda. Journal of Product Innovation Management, 36, 124-148.

MUGEL, O., GURVIEZ, P. \& DECROP, A. 2019. Eudaimonia Around the Kitchen: A Hermeneutic Approach to Understanding Food Well-Being in Consumers' Lived Experiences. Journal of Public Policy \& Marketing, 38, 280-295.

NESLIN, S. 2002. Sales Promotion. In: WEITZ, B. \& WENSLEY, R. (eds.) Handbook of Marketing. London: Sage.

OSTROM, A. L., PARASURAMAN, A., BOWEN, D. E., PATRÍCIO, L. \& VOSS, C. A. 2015. Service Research Priorities in a Rapidly Changing Context. Journal of Service Research, 18, 127-159.

PARKINSON, J., DUBELAAR, C., CARINS, J., HOLDEN, S., NEWTON, F. \& PESCUD, M. 2017. Approaching the wicked problem of obesity: an introduction to the food system compass. Journal of Social Marketing, 7, 387-404.

RAFIQ, M. \& AHMED, P. K. 1995. Using the 7Ps as a generic marketing mix. Marketing Intelligence \& Planning. MCB UP Ltd.

ROBERTO, C. A., SWINBURN, B., HAWKES, C., HUANG, T. T., COSTA, S. A., ASHE, M., ZWICKER, L., CAWLEY, J. H. \& BROWNELL, K. D. 2015. Patchy progress on obesity prevention: emerging examples, entrenched barriers, and new thinking. The Lancet, 385, 2400-2409.

SANDERS, E. B. N. \& STAPPERS, P. J. 2008. Co-creation and the new landscapes of design. Co-design, 4, 5-18.

SCOTT, M. L. \& VALLEN, B. 2019. Expanding the Lens of Food Well-Being: An Examination of Contemporary Marketing, Policy, and Practice with an Eye on the Future. Journal of Public Policy \& Marketing, 38, 127-135.

SONNTAG, D., SCHNEIDER, S., MDEGE, N., ALI, S. \& SCHMIDT, B. 2015. Beyond Food Promotion: A Systematic Review on the Influence of the Food Industry on Obesity-Related Dietary Behaviour among Children. Nutrients, 7, 8565-8576. 
STATISTICS, A. B. O. 2019. Australian Demographic Statistics, Dec 2018 [Online]. Available:

https://www.abs.gov.au/ausstats/abs@.nsf/0/D56C4A3E41586764CA2581A7001589 3E? Opendocument [Accessed 9 August 2019].

SWINBURN, B. A., SACKS, G., HALL, K. D., MCPHERSON, K., FINEGOOD, D. T., MOODIE, M. L. \& GORTMAKER, S. L. 2011. The global obesity pandemic: shaped by global drivers and local environments. The Lancet, 378, 804-814.

TAN, P. J., CORSI, A., COHEN, J., SHARP, A., LOCKSHIN, L., CARUSO, W. \& BOGOMOLOVA, S. 2018. Assessing the sales effectiveness of differently located endcaps in a supermarket. Journal of Retailing and Consumer Services, 43, 200-208.

TRISCHLER, J., DIETRICH, T. \& RUNDLE-THIELE, S. In press. Co-design: From expertto user-driven ideas in public service design. Public Management Review.

VAN'T RIET, J. 2013. Sales effects of product health information at points of purchase: A systematic review. Public Health Nutrition, 16, 418-429. 